\title{
Cataract subtype risk factors identified from the Korea National Health and Nutrition Examination survey 2008-2010
}

Tyler Hyung Taek Rim ${ }^{1 \dagger}$, Min-hyung Kim ${ }^{2,3 \dagger}$, Woon Cho Kim ${ }^{4}$, Tae-Im Kim ${ }^{1,5}$ and Eung Kweon Kim 1,5,6,7*

\begin{abstract}
Background: To assess the socio-demographic and health-related risk factors associated with cataract subtypes in Korea.

Methods: A total of 11,591 participants (aged $\geq 40$ years) were selected from the Korean National Health and Nutrition Examination Survey between 2008 and 2010. The Korean Ophthalmologic Society conducted detailed ophthalmologic examinations on these participants based on the Lens Opacity Classification System III. Risk factors for developing any type of cataract, and its subtypes (nuclear, cortical, posterior subcapsular and mixed), were identified from univariate and multivariate logistic regression analysis.

Results: The prevalence of cataracts was $40.1 \%(95 \% \mathrm{Cl}, 37.8$ - 42.3\%) in participants over 40 years old. Older age, lower monthly household income, lower education, hypercholesterolemia, hypertension, and diabetes mellitus (DM) were independent risk factors for development of any cataract. Older age, lower monthly household income, lower education, hypercholesterolemia, and DM were independent risk factors for development of pure cortical cataracts. Older age, lower education, metabolic syndrome, and DM were independent risk factors for development of pure nuclear cataracts. Older age and DM were independent risk factors for development of pure posterior subcapsular cataracts. Older age, lower monthly household income, lower education, and DM were independent risk factors for development of mixed cataracts.

Conclusion: Although socioeconomic disparities are related to cataract development, this study identified several "modifiable" risk factors that may help to lower the incidence of cataracts and associated vision loss. Improved control of blood pressure, blood, glucose, and cholesterol may help to reduce the incidence of cataracts in the general Korean population.
\end{abstract}

Keywords: Cataract, Cataract subtype, Cataract risk factors, KNHANES

\section{Background}

Age-related cataracts are the leading cause of blindness worldwide [1]. Identifying cataract risk factors can lead to various prevention and treatment options that will ultimately lessen the economic and public health burden of this disease. Previous studies have evaluated some of the modifiable and non-modifiable risk factors for

\footnotetext{
* Correspondence: eungkkim@yuhs.ac

${ }^{\dagger}$ Equal contributors

'Department of Ophthalmology, Yonsei University College of Medicine,

50 Yonsei-ro, Seodaemun-gu, Seoul, Korea

${ }^{5}$ Corneal Dystrophy Research Institute, Yonsei University College of Medicine, Seoul, Korea

Full list of author information is available at the end of the article
}

cataracts, including educational status [1,2], smoking [3], diabetes $[4,5]$, sunlight exposure [6,7], body mass index [8-10], steroid drug use [11], asthma [12], and estrogen replacement therapy [13-15]. Although these studies detail some of the pathophysiology of this multi-factorial disease in Western countries, risk factors specific to Asian populations are not well known. In fact, most studies that evaluated risk factors for specific cataract types (e.g., nuclear, cortical, and posterior subcapsular opacity [PSCO]) were performed in western countries [16-18]. A small but growing number of studies on specific cataract types in Asian countries have recently been performed in Japan, Taiwan, Singapore, and China [19-22].

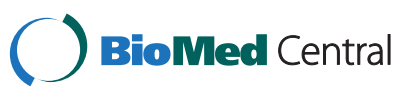


The Korea National Health and Nutrition Examination Survey (KNHANES) is a nationally representative survey conducted by the Ministry of Health and Welfare that provides data on vision status, healthcare use, and other sociodemographic factors. KNHANES results and statistics are readily available at http://knhanes.cdc.go.kr. Our objective, therefore, was to use ophthalmologic examination results from KNHANES to investigate the socio-demographic and health-related risk factors associated with cataract subtypes (Figure 1).

\section{Methods}

\section{Study design and population}

We have previously described our sampling, enumeration, visual acuity, and ocular examination procedures $[23,24]$. The Korea Center for Disease Control and Prevention (KCDCP) conducted a KNHANES series (I, II, and III) in 1998, 2001, and 2005, to examine general health and nutritional status of Koreans. For KNHANES IV (2007-2009), however, the survey became an annual rolling survey that used a stratified, multistage, clustered sampling method (based on $2005 \mathrm{Na}$ tional Census data) to randomly select 24,871 individuals across 500 national districts that represented the civilian, non-institutionalized South Korean population. KNHANES V (2010-2012) also randomly sampled households but across 576 national districts (192 enrolled each year). These households were also selected with a stratified, multi-stage clustered sampling method but were based on $2009 \mathrm{Na}$ tional Resident demographics. Surveys prior to KNHANES IV were able to be analyzed and could be considered a national representative sample after 3 years when the survey was completed, but rolling survey sampling methods were applied from KNHANES IV that allowed annual analysis of nationally representative data.

The KNHANES is divided into three parts: the Health Interview Survey, the Health Examination Survey, and the Nutrition Survey. Because the Korean Ophthalmologic Society participated in this survey after July 2008, ophthalmologic interviews and examinations were also

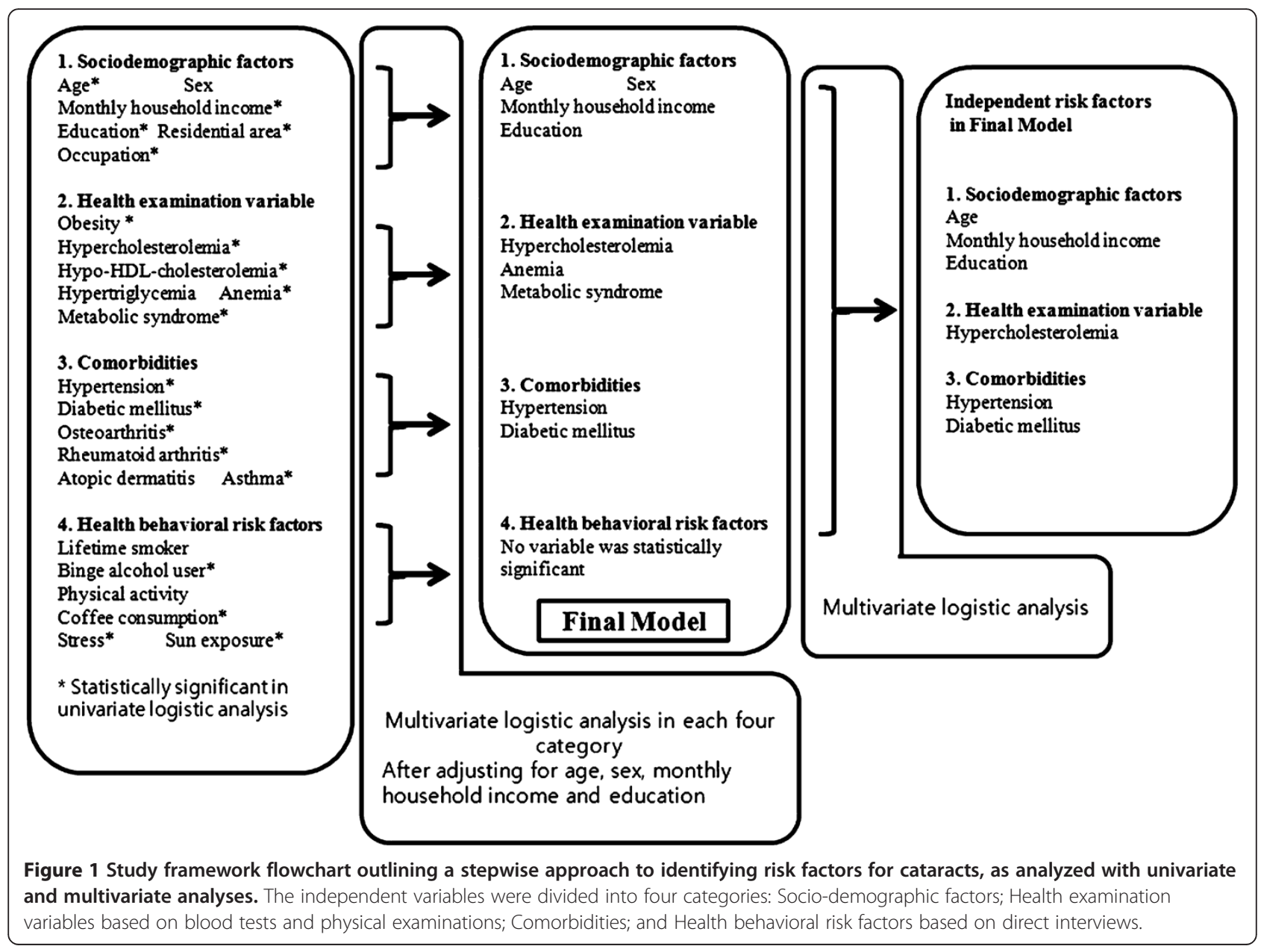


conducted with the same participants. All members of each selected household were asked to participate in the survey, with a participation rate of $82.0 \%$. We omitted participants less than 40 years old who had incomplete slit-lamp examinations, leaving a total of 11,591 participants from 2008 to 2010 (Figure 2). This survey was reviewed and approved by the Institutional Review Board of the Korea Centers for Disease Control and Prevention, and all participants provided written informed consent following the Declaration of Helsinki.

\section{Ophthalmologic examinations}

Designated ophthalmologists performed a structured slitlamp examination (Haag-Streit model BQ-900, Haag-Streit AG, Koeniz, Switzerland) to determine disease occurrence in the anterior segment of the eye (e.g., pterygium and cataract). Examinees were seated in the examination chair, resting their chin and forehead on the support. An illuminator was positioned behind the examinees' ears; the angle between the illuminator and the microscope was $30 \sim 45$ degrees with a $10 \times$ magnification. Without iridodilator usage, the characteristics of lens were assessed using slit lamp with proper brightness, height, and width. The overall characteristics of the lens were examined with a wider slit lamp, and the type and severity of the cataract was determined according to transparency, turbidity, pigments, vacuoles and nuclei. Each layer of the lens was examined with the focused slit lamp from the anterior capsule to the posterior capsule. Aphakia and pseudophakia were recorded separately, and excluded from the subtype analysis. The type of cataract was categorized according to Lens Opacity Classification System III (LOCS III) grading in both eyes, as nuclear, cortical, PSCO, or mixed (including anterior subcapsular). Standard pictures for each subtype were provided for each examiner (Figure 3). The quality of the survey was verified by the Epidemiologic Survey Committee of the Korean Ophthalmologic Society. Training of participating residents was periodically performed by acting staff members of the National Epidemiologic Survey Committee of the Korean Ophthalmologic Society.

\section{Outcome variable}

To identify risk factors for any type of cataract, we first verified cataract occurrence in a person with the presence of a nuclear, cortical, anterior subcapsular, or posterior subcapsular cataract in at least one eye. For statistical purposes, we also included pseudophakic and aphakic eyes as operated cataracts for calculating prevalence. To analyze and evaluate risk factors for each type of cataract, we defined the cataract subtypes as follows. Participants with no type of cataract in either phakic eye were defined as having no cataract. Individuals who had a cortical cataract in at least one eye were defined as having a pure cortical cataract. Individuals with either a nuclear cataract or a PSCO were similarly defined. Individuals with a mixed type cataract, which included an

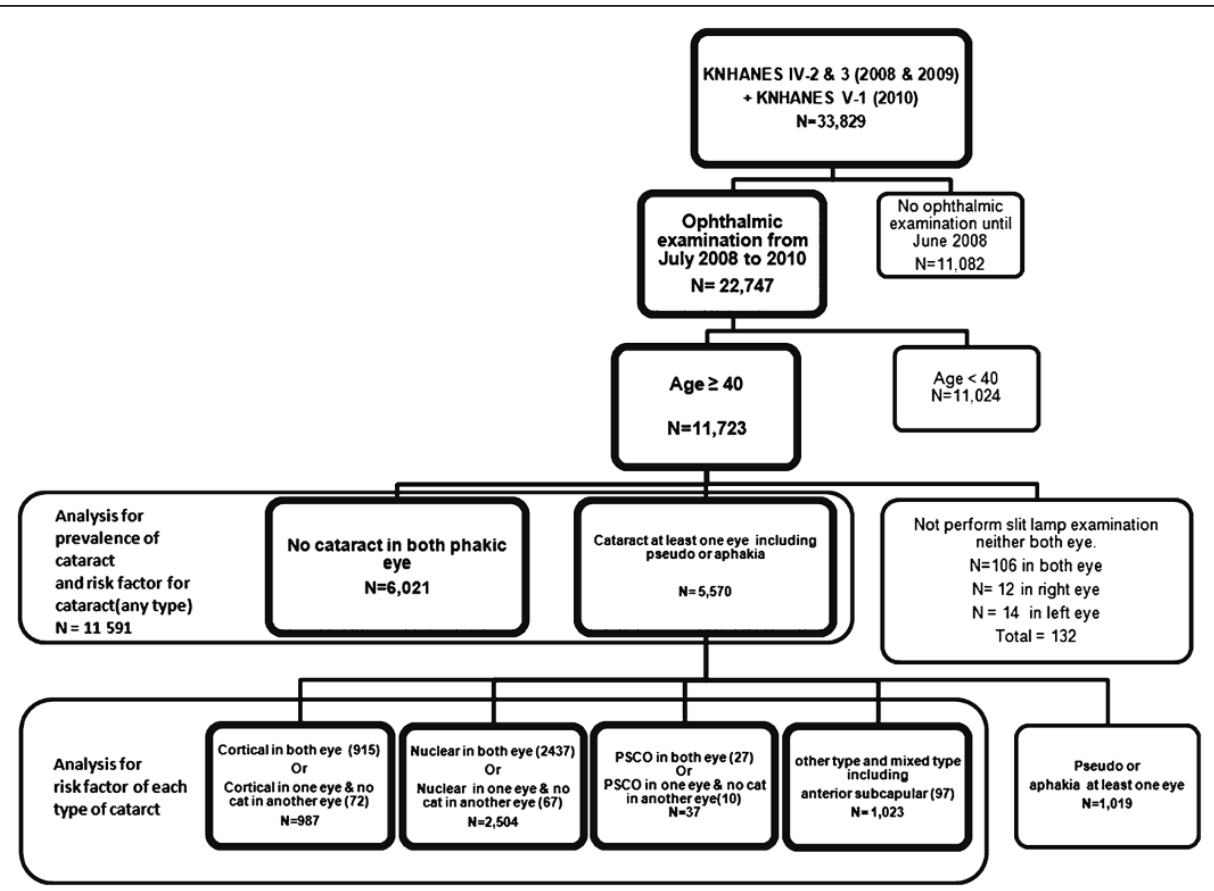

Figure 2 Flow diagrams showing selection of the study population. 

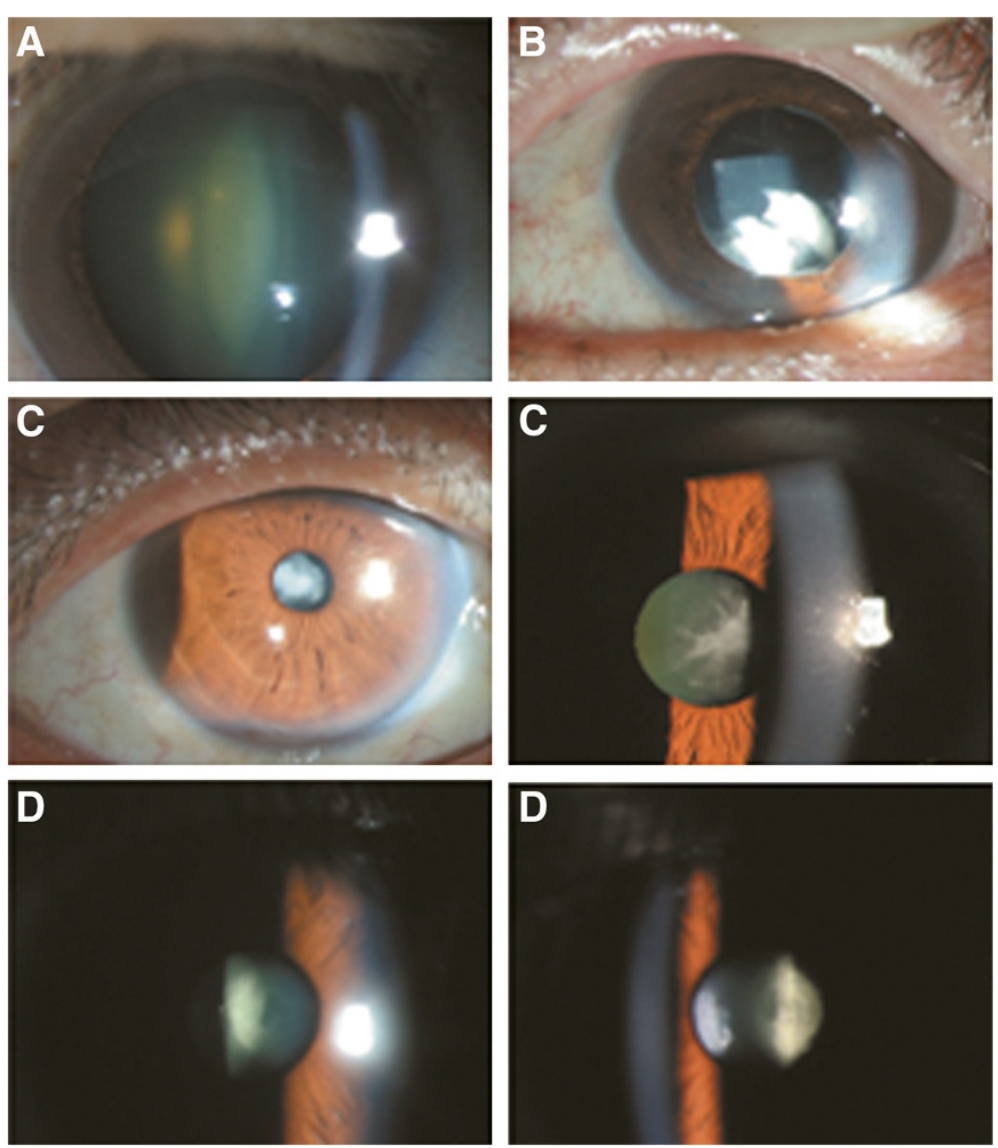

Figure 3 Standard pictures for each subtype. A. Nuclear type, B. Cortical type, C. Anterior capsular type, D. Posterior capsular type.

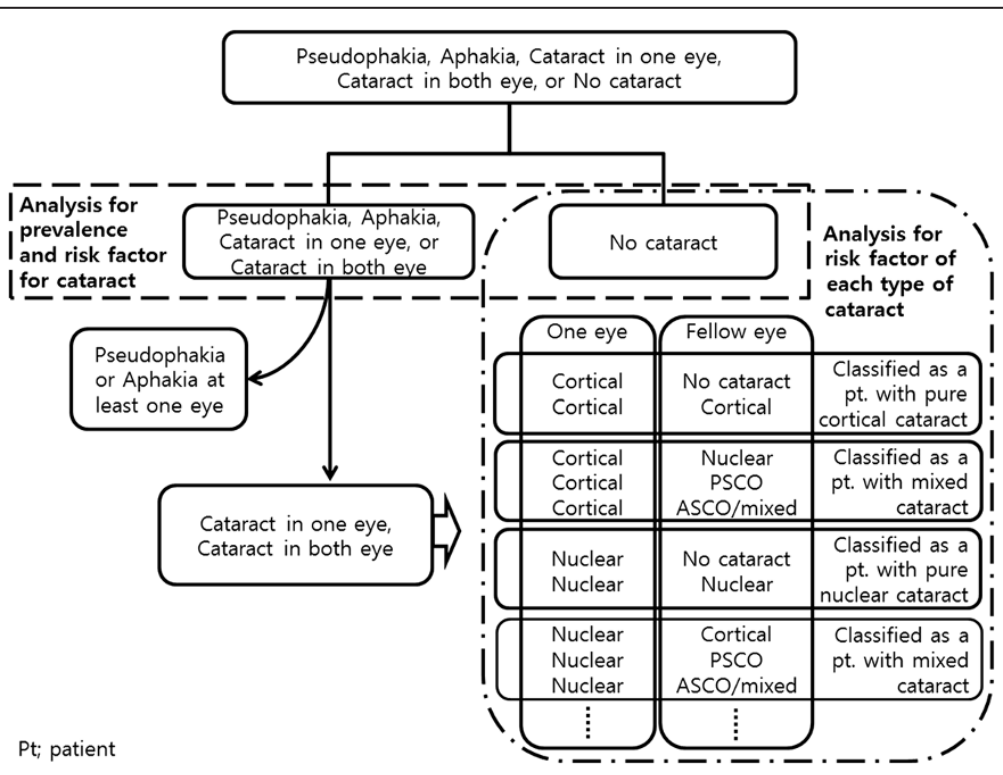

Figure 4 Flow chart shows how to classify the each subtype of cataract in detail. 
Table 1 Characteristics of the study population $(\mathrm{N}=11,591)$

1. Socio-demographic factors

Age (years)

40-49

50-59

60-69

70-80

$80+$

Sex

Men

Women

Monthly household income

$$
\begin{aligned}
& \text { Lowest quintile } \\
& \text { 2nd to 4th quintile } \\
& \text { Highest quintile }
\end{aligned}
$$

Education

Elementary school

Middle school

High school

University or higher

Residential area

$$
\text { Urban }
$$

Rural

Occupation

Administrator, management, and professional

Business and financial operations

Sales and related

Farming, fishing, and forestry

Installation, maintenance, and repair

Laborer

Unemployed

\section{Health examination variable}

Obesity

$$
\text { Underweight }
$$

Normal

Obesity

Hypercholesterolemia

$$
\text { No }
$$

Yes

Hypo-HDL-cholesterolemia

$$
\text { No }
$$

Yes

Hypertriglycemia

No

Yes

\section{$n$}

3353

3019

2813

1959

447

5000

6591

3108

5946

2355

4644

1779

3111

1929

8124

3467

883

548

1416

1539

1089

1208

4761

7223

3980

357

8978

1695

7613

3122

7257

1547
Table 1 Characteristics of the study population $(\mathrm{N}=11,591)$ (Continued)

Anemia

28.9

26.1

24.3

16.9

3.9

\section{Comorbidities}

Hypertension

43.1

56.9

No

8033

69.3

Yes

3472

30.0

Diabetic mellitus

26.8

No

10237

88.3

Yes

1267

10.9

20.3

Osteoarthritis

No

$9596 \quad 82.8$

40.1

15.4

26.8

16.6

Yes

1907

16.5

Rheumatoid arthritis

No

$11161 \quad 96.3$

Yes

342

3.0

Atopic dermatitis

No

11339

97.8

Yes

163

1.4

Asthma

No

$11083 \quad 95.6$

Yes

421

3.6

\section{Health behavioral risk factors}

Lifetime smoker

$$
\text { No }
$$

6797

58.6

10.4

Yes

4704

Binge alcohol user

No

$8375 \quad 72.3$

Yes

3140

62.3

Physical activity of moderate intensity

$$
\text { never }
$$

11078

95.6

more than once in a week

394

3.4

Coffee consumption

77.5

Never

1393

12.0

14.6

1-6 cups per week

2236

19.3

$\geq 7$ cups per week

6476

55.9

$65.7 \quad$ Stress

26.9

Least stressful

2249

19.4

Moderately stressful

8671

74.8

62.6

Extremely stressful

557

4.8 
Table 1 Characteristics of the study population $(\mathrm{N}=11,591)$ (Continued)

\begin{tabular}{rrr}
\hline Sun exposure & & \\
$<5 \mathrm{hr} /$ day & 8182 & 70.6 \\
$\geq 5 \mathrm{hr} /$ day & 3286 & 28.4 \\
\hline
\end{tabular}

anterior subcapsular type in at least one eye, were defined as having a mixed type cataract (Figure 2). Figure 4 shows how the cataract subtypes were categorized in detail using a flow chart.

\section{Independent variables}

The independent variables were divided into four categories: (1) socio-demographic factors, (2) health examination variables, (3) comorbidities, and (4) health behavioral risk factors. The income per adult equivalent was calculated with the following formula: household income divided by the square root of the number of people in the household [25]. Binge alcohol users were defined as either men who consumed more than seven drinks on a single occasion or women who consumed more than five drinks on a single occasion, both at a prevalence of at least once per month

Table 2 The prevalence of cataract

\begin{tabular}{|c|c|c|}
\hline & $\%$ & $95 \% \mathrm{Cl}$ \\
\hline \multicolumn{3}{|l|}{ All } \\
\hline $40 \sim 49$ & 10.4 & $(8.4-12.4)$ \\
\hline $50 \sim 59$ & 33.1 & $(29.6-36.6)$ \\
\hline $60 \sim 69$ & 69.4 & $(66.0-72.8)$ \\
\hline $70 \sim 80$ & 91.2 & $(89.2-93.3)$ \\
\hline $80 \sim$ & 97.9 & $(96.4-99.5)$ \\
\hline$\geq 40^{*}$ & 40.1 & $(37.9-42.3)$ \\
\hline$\geq 50$ & 58.1 & $(55.5-60.8)$ \\
\hline$\geq 60$ & 80.2 & $(77.9-82.4)$ \\
\hline$\geq 70$ & 92.7 & $(91.0-94.3)$ \\
\hline$\geq 80$ & 97.9 & $(96.4-99.5)$ \\
\hline \multicolumn{3}{|l|}{ Men } \\
\hline $40 \sim 49$ & 10.7 & $(8.5-13.0)$ \\
\hline $50 \sim 59$ & 34.6 & $(30.4-38.8)$ \\
\hline $60 \sim 69$ & 68.4 & $(64.2-72.7)$ \\
\hline $70 \sim 80$ & 89.6 & $(86.6-92.5)$ \\
\hline $80 \sim$ & 96.7 & $(93.7-99.7)$ \\
\hline \multicolumn{3}{|l|}{ Women } \\
\hline $40 \sim 49$ & 10.0 & $(7.7-12.3)$ \\
\hline $50 \sim 59$ & 31.6 & $(27.8-35.4)$ \\
\hline $60 \sim 69$ & 70.3 & $(66.5-74.0)$ \\
\hline $70 \sim 80$ & 92.3 & $(90.0-94.6)$ \\
\hline $80 \sim$ & 98.5 & $(97.0-100.0)$ \\
\hline
\end{tabular}

${ }^{*} \geq X=$ subjects aged $X$ years and older.
[26]. Respondents who reported that they were current smokers and had smoked at least 100 cigarettes in their lifetime were considered lifetime smokers [27]. We used the World Health Organization BMI-defined obesity standard (international standard) to define both obesity and underweight ( $\geq 25 \mathrm{~kg} / \mathrm{m} 2$ and $<18 \mathrm{~kg} / \mathrm{m} 2$, respectively) for adults. Hypercholesterolemia was defined for any of the following three cases: 1) a total cholesterol level $>240 \mathrm{mg} / \mathrm{dL}$ from a blood test taken after fasting, 2) the use of lipid-lowering drugs, or 3) diagnosis of dyslipidemia by a physician. HDLcholesterol levels $<40 \mathrm{mg} / \mathrm{dL}$ were defined as hypo-HDLcholesterolemia and triglyceride levels $>200 \mathrm{mg} / \mathrm{dL}$ were defined as hypertriglycemia. In this study, subjects who fulfilled at least three of the following five components were defined as exhibiting metabolic syndrome: 1) central obesity (waist circumference: $\geq 90 \mathrm{~cm}$ for Korean men, $\geq 85 \mathrm{~cm}$ for Korean women; The Korean Society for the Study of Obesity proposed $90 \mathrm{~cm}$ and $85 \mathrm{~cm}$ as the appropriate abdominal circumferences for obesity consideration in Korean men and women, respectively [28,29]), 2) hypertriglyceridemia ( $\geq 150 \mathrm{mg} / \mathrm{dL})$, 3) low HDL cholesterol (men $<40 \mathrm{mg} / \mathrm{dL}$, women $<50 \mathrm{mg} / \mathrm{dL}$ ), 4) high blood pressure (systolic blood pressure $\geq 130 \mathrm{mmHg}$, diastolic blood pressure $\geq 85 \mathrm{mmHg}$, or receiving hypertension drug treatment) and 5) hyperglycemia (fasting serum glucose $\geq 100 \mathrm{mg} / \mathrm{dL}$ ).

\section{Statistical methods}

We report descriptive statistics for each response. We determined age-specific prevalence of cataracts in Koreans with weighting recommended in KNHANES IV and V-1. To weight KNHANES IV in accordance to guidelines in the 2005 Census of Korea, we performed a post-stratification adjustment to response and extraction rates that included the same distribution of the 2005 Korean population, according to sex and age groups and at 5-year intervals. Finally, the sum of the weight of KNHANES IV was considered equal to that in the Korean population as of 2005. We weighted KNHANES V-1 in a similar manner but based it on the 2010 Korean population and in accordance with the 2010 Census of Korea.

We used a three-step, multi-dimensional approach to identify cataract risk factors. First, we calculated unadjusted odds ratios and 95\% CIs with univariate logistic regression analysis. Second, we applied multivariate logistic regression analysis on all variables in each category, after adjusting for age, sex, monthly household income, and education. Finally, we used multivariate logistic regression analysis to determine independent risk factors. All risk factors that were identified by multivariate analysis were included in the final multivariate analysis (Final Model; middle column in Figure 2). All 
Table 3 Factors associated with risk of developing cataracts - univariate analysis $(N=11,591)$

\begin{tabular}{|c|}
\hline 1. Socio-demographic factors \\
\hline Age (years) \\
\hline $40-49$ \\
\hline $50-59$ \\
\hline $60-69$ \\
\hline $70-80$ \\
\hline $80+$ \\
\hline Sex \\
\hline Men \\
\hline Women \\
\hline Monthly household income \\
\hline Lowest quintile \\
\hline 2nd to 4 th quintile \\
\hline Highest quintile \\
\hline Education \\
\hline Elementary school \\
\hline Middle school \\
\hline High school \\
\hline University or higher \\
\hline Residential area \\
\hline Urban \\
\hline Rural \\
\hline Occupation \\
\hline $\begin{array}{l}\text { Administrator, management, } \\
\text { and professional }\end{array}$ \\
\hline Business and financial operations \\
\hline Sales and related \\
\hline Farming, fishing, and forestry \\
\hline $\begin{array}{l}\text { Installation, maintenance, } \\
\text { and repair }\end{array}$ \\
\hline Laborer \\
\hline Unemployed \\
\hline
\end{tabular}

\section{Health examination variable}

Obesity

Underweight
Normal
Obesity

Hypercholesterolemia

$$
\text { No }
$$$$
\text { Yes }
$$

Hypo-HDL-cholesterolemia

$$
\text { No }
$$$$
\text { Yes }
$$
Univariate OR

\section{0}

2.1

1.0 (ref)

1.5

1.0 (ref)

1.4

Table 3 Factors associated with risk of developing cataracts - univariate analysis $(\mathbf{N}=\mathbf{1 1}, \mathbf{5 9 1})$ (Continued)

Hypertriglycemia $95 \% \mathrm{C}$

1.0 (ref)

$\begin{array}{ccc}4.3 & 3.8-5.0 & <0.01 \\ 21.0 & 18.3-24.1 & <0.01 \\ 92.6 & 76.4-112.4 & <0.01 \\ 344.5 & 187.4-633.1 & <0.01 \\ & & \\ 1.0 \text { (ref) } & & \\ 1.0 & 1.0-1.1 & 0.35\end{array}$

1.0 (ref)

0.2

0.2-0.3 <0.01

0.1

$0.1-0.1<0.01$

1.0 (ref)

$\begin{array}{lll}0.3 & 0.3-0.4 & <0.01 \\ 0.2 & 0.2-0.2 & <0.01 \\ 0.1 & 0.1-0.1 & <0.01\end{array}$

1.0 (ref)

1.8

$1.6-1.9<0.01$

1.0 (ref)

$\begin{array}{ccc}0.9 & 0.7-1.2 & 0.49 \\ 1.6 & 1.3-1.9 & <0.01 \\ 6.8 & 5.6-8.3 & <0.01 \\ 1.6 & 1.3-2.0 & <0.01 \\ & & \\ 3.6 & 2.9-4.4 & <0.01 \\ 6.5 & 5.5-7.8 & <0.01\end{array}$

0.9-1.1 0.80

$1.7-2.7<0.01$

$1.3-1.6<0.01$
No

Yes

Anemia

No

Yes

Metabolic syndrome

No

Yes

\section{Comorbidities}

Hypertension

No

Yes

Diabetic mellitus

No

Yes

Osteoarthritis

No

Yes

Rheumatoid arthritis

No

Yes

Atopic dermatitis

No

Yes

Asthma

No

Yes

4. Health behavioral risk factors

Lifetime smoker

$$
\text { No }
$$$$
\text { Yes }
$$

1.0 (ref)

1.0

Binge alcohol user

$$
\text { No }
$$

Yes

1.0 (ref)

$1.1 \quad 1.0-1.2 \quad 0.13$

1.0 (ref)

$1.3 \quad 1.2-1.5<0.01$

1.0 (ref)

2.1

$1.9-2.2<0.01$

1.0 (ref)

$3.1 \quad 2.8-3.3<0.01$

1.0 (ref)

3.1

$2.7-3.5<0.01$

1.0 (ref)

2.8

$2.5-3.1<0.01$

1.0 (ref)

$2.1 \quad 1.7-2.6<0.01$

1.0 (ref)

$\begin{array}{lll}0.7 & 0.5-1.0 & 0.06\end{array}$

1.0 (ref)

1.9

$1.6-2.3<0.01$

Physical activity of moderate intensity

Never 1.0 (ref)

$>5$ times per week

1.1

$0.9-1.3$

0.51

Coffee consumption

$$
\begin{aligned}
& \text { Never } \\
& \text { 1-6 cups per week } \\
& \geq 7 \text { cups per week }
\end{aligned}
$$

1.0 (ref)

$\begin{array}{lll}0.7 & 0.6-0.8 & <0.01 \\ 0.5 & 0.4-0.5 & <0.01\end{array}$




\begin{tabular}{|c|c|c|c|}
\hline \multicolumn{4}{|l|}{ Stress } \\
\hline Least stress & 1.0 (ref) & & \\
\hline Moderately stressful & 0.4 & $0.4-0.5$ & $<0.01$ \\
\hline Extreme stress & 0.6 & $0.5-0.7$ & $<0.01$ \\
\hline \multicolumn{4}{|l|}{ Sun exposure } \\
\hline$<5$ hr/day & 1.0 (ref) & & \\
\hline$\geq 5$ hr/day & 1.7 & $1.6-1.9$ & $<0.01$ \\
\hline
\end{tabular}

statistical tests were two-sided and performed with Stata/ SE 12.1 software (StataCorp, College Station, TX, USA).

\section{Results}

\section{Baseline characteristics of the study population}

The mean ( \pm standard error) age of the final 11,591 participants was $58.4 \pm 0.1$ years. Of those participants, $43.1 \%$ were men, $70.1 \%$ were living in an urban area, $14.6 \%$ had hypercholesterolemia, 9.9\% had anemia, 41.5\% had metabolic syndrome, $30.0 \%$ had hypertension, and $10.9 \%$ had diabetes mellitus (DM). Table 1 lists the detailed baseline characteristics of the study population.

\section{Cataract prevalence}

Table 2 provides the prevalence of cataract specific to age and sex. The listed data are percentages of prevalence and the 95\% confidence interval (CI). The overall prevalence of cataracts in subjects aged 40 years and older was $40.1 \%$ (95\% CI, 37.8-42.3\%). The prevalence for each type of cataract were $7.4 \%$ (95\% CI, 6.4-8.5\%) for pure cortical type, $20.3 \%$ (95\% CI, 18.2-22.3\%) for pure nuclear type, $0.3 \%$ ( $95 \% \mathrm{CI}, 0.2-0.5 \%$ ) for pure posterior subcapsular type, and 7.5\% (95\% CI, 6.6-8.4\%) for mixed type.

\section{Factors associated with cataracts}

The factors from the univariate analysis that were significantly associated with cataracts (see Table 3 for odd ratios and 95\% CIs) included all variables except sex, hypertriglycemia, atopic dermatitis, lifetime smoking, and physical activity (left column in Figure 1). In the multivariate analysis of all socio-demographic factors (Table 4), four risk factors were statistically significant: age, sex, monthly household income and education. Participants with hypercholesterolemia, anemia, and metabolic syndrome were more likely to have cataracts in their health examination variables, after adjusting for the above four significant socio-demographic factors. For comorbidities, participants with either hypertension or DM were more likely to have cataracts after adjusting for age, sex, monthly household income, and education. For the multivariate regression analysis, none of the health behavioral risk variables were significantly related to cataract occurrence.

Significant risk factors for cataract were combined into a final model in Figure 1. In the multivariate analysis for cataract based on the final model (Table 5), three risk factors were statistically significant among sociodemographic variables: (1) age [age 40-49=1.0 (ref), adjusted odds ratio (aOR) of age 50-59 = 3.5 (95\% CI, 3.04.1), aOR of age $60-69=14.3$ (95\% CI, 12.1-16.8), aOR of age $70-80=53.1(95 \% \mathrm{CI}, 42.5-66.4)$, and aOR of age $80+=194.1$ (95\% CI, 94.5-398.6)]; (2) monthly household income $[1.0(\mathrm{ref})$ in the lowest quintile, aOR of the 2nd to 4th quintile $=0.9$ (95\% CI, 0.7-1.0), and aOR of the highest quintile $=0.7$ (95\% CI, 0.6-0.9)]; and (3) education [1.0 (ref) in elementary school, aOR of middle school $=0.8$ (95\% CI, 0.7-0.9), aOR of high school $=0.7$ (95\% CI, 0.6-0.8), and aOR of either university or higher = 0.6 (95\% CI, 0.5-0.7)]. Participants with hypercholesterolemia $(\mathrm{aOR}=1.2 ; 95 \% \mathrm{CI}, 1.0-1.3)$ were more likely to have cataracts in their health examination variables. For comorbidities, participants with hypertension $(\mathrm{aOR}=1.1 ; 95 \% \mathrm{CI}$, 1.0-1.3) or DM $(\mathrm{aOR}=1.6 ; 95 \% \mathrm{CI}, 1.3-1.9)$ were more likely to have cataracts. In the multivariate analysis for cataract subtypes (Table 6), five factors were statistically significant for the pure cortical cataract type: age, monthly household income, education, hypercholesterolemia, and DM. For the pure nuclear type of cataract, four factors were statistically significant: age, education, metabolic syndrome, and DM. For the pure posterior subcapsular opacity, two factors were statistically significant: age and DM. Finally, for the mixed type of cataract, four factors were statistically significant: age, monthly household income, education, and DM.

Table 7 presents the effect of hypertension and diabetes mellitus (DM) on the risk of cataract. RRs with CIs are presented separately for the $D M$ group $(R R=1.7$, 95\% CI, 1.4-2.2), for the hypertension group ( $R R=1.2$, 95\% CI, 1.1-1.3), and for both groups combined ( $R R=$ 2.0, 95\% CI, 1.6-2.5); subjects without DM or hypertension were the reference group.

\section{Discussion}

This study assessed results from a national health survey to provide epidemiologic data on the prevalence of cataract among Koreans aged 40 years and older. In doing so, we found a prevalence of $40.1 \%$ for any cataract or cataract surgery. Additionally, our study showed that the frequencies of cataract between both genders were similar, and that hypertension and DM could be modifiable risk factors.

Much of the literature does not report the prevalence of each subtype of cataract. Among the articles that have reported on the prevalence of each subtype, the studied age groups vary, some of which included those over the 
Table 4 Factors associated with risk of developing cataracts after adjusting for significant sociodemographic factors* - multivariate analysis for each variable cluster $(\mathrm{N}=11,591)$

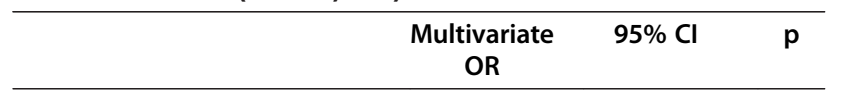

1. Socio-demographic factors

Age (years)

40-49

$50-59$

60-69

70-80

$80+$

Sex

$$
\text { Men }
$$

Women

Monthly household income

$$
\begin{aligned}
& \text { Lowest quintile } \\
& \text { 2nd to 4th quintile }
\end{aligned}
$$

Highest quintile

Education

Elementary school

Middle school

High school

University or higher

Residential area

$$
\text { Urban }
$$

Rural

Occupation

Administrator, management, and professional

Business and financial operations

Sales and related

Farming, fishing, and forestry

Installation, maintenance,

and repair

Laborer

Unemployed

2. Health examination variable

Obesity

Underweight
Normal
Obesity

Hypercholesterolemia

$$
\text { No }
$$$$
\text { Yes }
$$

1.0 (ref)

$\begin{array}{ccc}3.7 & 3.2-4.3 & <0.01 \\ 14.9 & 12.7-17.4 & <0.01 \\ 57.3 & 46.0-71.3 & <0.01 \\ 192.7 & 103.6-358.4 & <0.01 \\ & & \\ 1.0 \text { (ref) } & & \\ 0.9 & 0.8-1.0 & 0.02\end{array}$

$$
0.9
$$

$0.8-1.0$

0.02

$\begin{array}{ccc}1.0 \text { (ref) } & & \\ 0.9 & 0.7-1.0 & 0.04 \\ 0.7 & 0.6-0.9 & <0.01\end{array}$

1.0 (ref)

$\begin{array}{ccc}0.8 & 0.7-0.9 & <0.01 \\ 0.7 & 0.6-0.8 & <0.01 \\ 0.6 & 0.5-0.7 & <0.01 \\ & & \\ 1.0 \text { (ref) } & & \\ 1.0 & 0.9-1.2 & 0.57\end{array}$

1.0 (ref)

1.0

$\begin{array}{ll}0.8-1.4 & 0.78 \\ 0.8-1.3 & 0.79 \\ 0.8-1.4 & 0.49 \\ 0.7-1.3 & 0.83 \\ & \\ 0.8-1.4 & 0.54 \\ 1.0-1.5 & 0.09\end{array}$

1.0 (ref)

1.0

0.8-1.1

0.44

0.9-1.9

0.10

1.0 (ref)

1.2

$1.0-1.4$

Table 4 Factors associated with risk of developing cataracts after adjusting for significant sociodemographic factors* - multivariate analysis for each variable cluster $(\mathrm{N}=\mathbf{1 1}, \mathbf{5 9 1})$ (Continued)

Hypo-HDL-cholesterolemia

No

Yes

Hypertriglycemia

$$
\begin{array}{r}
\text { No } \\
\text { Yes } \\
\text { Anemia } \\
\text { No } \\
\text { Yes }
\end{array}
$$

No

Metabolic syndrome

$$
\text { No }
$$$$
\text { Yes }
$$

\section{Comorbidities}

Hypertension

$$
\text { No }
$$

Yes

Diabetic mellitus

$$
\text { No }
$$

Yes

Osteoarthritis

$$
\begin{aligned}
& \text { No } \\
& \text { Yes }
\end{aligned}
$$

Rheumatoid arthritis

$$
\text { No }
$$

Yes

Atopic dermatitis

$$
\begin{array}{r}
\text { No } \\
\text { Yes } \\
\text { Asthma } \\
\text { No }
\end{array}
$$$$
\text { Yes }
$$

4. Health behavioral risk factors

Lifetime smoker

$$
\text { No }
$$

Yes

Binge alcohol user

$$
\text { No }
$$$$
\text { Yes }
$$

1.0 (ref)

1.0

$0.8-1.1$

1.0 (ref)

$\begin{array}{lll}0.9 & 0.7-1.0 & 0.10\end{array}$

1.0 (ref)

1.2

$1.0-1.5$

0.05

1.0 (ref)

1.2

$1.1-1.4$

$<0.01$

1.0 (ref)

$1.2 \quad 1.0-1.3<0.01$

1.0 (ref)

$1.7 \quad 1.4-2.0<0.01$

1.0 (ref)

1.1

$0.9-1.2 \quad 0.31$

1.0 (ref)

$1.1 \quad 0.8-1.4 \quad 0.55$

1.0 (ref)

$0.9 \quad 0.6-1.3 \quad 0.45$

1.0 (ref)

$\begin{array}{lll}1.0 & 0.8-1.3 \quad 0.92\end{array}$

Physical activity of moderate intensity

Never $\quad 1.0$ (ref)

$>5$ times per week

1.0

$0.8-1.3$

0.93 


\begin{tabular}{|c|c|c|c|}
\hline \multicolumn{4}{|l|}{ Coffee consumption } \\
\hline Never & 1.0 (ref) & & \\
\hline 1-6 cups per week & 0.9 & $0.8-1.1$ & 0.50 \\
\hline$\geq 7$ cups per week & 0.9 & $0.7-1.0$ & 0.09 \\
\hline \multicolumn{4}{|l|}{ Stress } \\
\hline Least stress & 1.0 (ref) & & \\
\hline Moderate stress & 0.9 & $0.8-1.0$ & 0.07 \\
\hline Extreme stress & 1.1 & $0.8-1.4$ & 0.59 \\
\hline \multicolumn{4}{|l|}{ Sun exposure } \\
\hline$<5$ hr/day & 1.0 (ref) & & \\
\hline$\geq 5 \mathrm{hr} /$ day & 1.1 & $1.0-1.2$ & 0.09 \\
\hline
\end{tabular}

age of $40[20-22,30]$ or even those over the age of 50 [19], 60 [31], or 65 [32]. Moreover, the grading systems utilized for the assessment of cataract also vary; LOCS III was used in only some of the studies [20,22,30-32]. The focus of the present study was not to compare the prevalences of cataract reported in the literature, but rather to assess the prevalence in the Korean population and investigate potential risk factors.

\section{Prevalence of cataracts in Asian Countries}

The prevalence of cataracts in Asian countries, including Singapore [20,22], Taiwan [32], Japan [19], China [21], Myanmar [30], India [31] and Pakistan [33] ranged from $20 \%$ [33] to $63 \%$ [31]. For the subtypes of cataracts in Asian countries, cortical cataract prevalence ranged from $7.1 \%$ [31] to $23.9 \%$ [22], nuclear cataract prevalence ranged from $22.6 \%$ [22] to $50.3 \%$ [21], and PSCO prevalence ranged from $4.3 \%$ [21] to $18.7 \%$ [31]. Compared to prevalence values reported in previous studies, those found in our study for pure cortical, nuclear, or PSCO types were lower, whereas more cataracts were classified as the mixed type, possibly because we used a more strict classification system for evaluating the risk factors associated with the pure subtype. In our study, the prevalence of the pure nuclear type was more than twice that of the pure cortical type. This did not surprise us because many previous studies, including studies from Taiwan [32], China [21], Myanmar [30] and India [31] reported a higher prevalence of the nuclear type than the cortical type. Furthermore, the Indian study [31] compared its northern population to its southern population and concluded that the northern population had a higher prevalence of the nuclear type cataract (42.2\% versus $34.5 \%)$, which was probably due to environmental factors such as climate and/or ultraviolet exposure. Some of these studies discussed prevalence differences between populations, despite some debate as to whether differences result from environmental or racial/genetic differences [19,34].

Age

Of all significant factors from this study, age was the most significant risk factor for cataracts, as in previous studies $[17,21,30,31,35]$. With increased age, one is more likely to suffer from cumulative exposure to numerous risk factors, especially environmental factors, such as either longer duration of radiation or oxidative damage [36]. We found it interesting that our odds ratio for the mixed type was significantly higher than that for either the cortical or the nuclear type (Table 6). This result implies that a patient with a mixed type cataract is most likely to be an older person, as compared to patients with pure cortical, nuclear, or PSCO cataracts. As this study is a cross-sectional study, we can show neither its time-sequence nor any causal relationships between age and mixed type cataracts. The mixed type might have resulted from multiple pathogenesis from exposure to multiple risk factors; therefore, the older person, with presumably more exposure to various pathogenesis and risk factors, would be linked to the mixed type cataract.

\section{Socioeconomic status and educational status}

Others have investigated socioeconomic status and educational status risk factors for cataracts, with various results $[2,37]$. In our study, individuals with lower incomes were associated with pure cortical and mixed type cataracts, whereas lower education status was associated with pure cortical and nuclear type cataracts. Although educational status could have a dependent relationship with socioeconomic status, our study actually shows it to be an independent risk factor for cataracts (Table 5). Socioeconomic status and educational status are general ways of living that could produce risk factors that may not yet be described. Here, we can only suggest the possibility of more risk factors associated with socioeconomic status and/or educational status.

\section{DM and hypertension}

Our study reconfirms the positive relationship that hypertension and DM have with cataract prevalence $[1,5,38-40]$. Many studies show DM to be related to cortical, nuclear, posterior subcapsular, and mixed type cataracts $[4,5,41,42]$. Our study also showed prominent odds ratios for all cataract subgroups. The overall odds ratio for DM and any type of cataract was the second highest $(\mathrm{aOR}=1.6 ; 95 \% \mathrm{CI}, 1.3-1.9)$, and the odds ratio for the posterior subcapsular type was the highest in the subgroup analysis $(\mathrm{aOR}=2.7 ; 95 \% \mathrm{CI}, 1.1-6.9)$.

According to Strengthening the Reporting of Observational Studies in Epidemiology (STROBE), we should consider hypertension and DM effect modifications. 
Table 5 Factors associated with risk of cataract development - Final model $(n=11,591)$

\begin{tabular}{|c|c|c|c|c|}
\hline & Univariate OR & Multivariate OR & $95 \% \mathrm{Cl}$ & $\mathbf{p}$ \\
\hline \multicolumn{5}{|c|}{ 1. Socio-demographic factors } \\
\hline \multicolumn{5}{|l|}{ Age (years) } \\
\hline $40-49$ & 1.0 (ref) & 1.0 (ref) & & \\
\hline $50-59$ & 4.3 & 3.5 & $3.0-4.1$ & $<0.01$ \\
\hline $60-69$ & 21.0 & 14.3 & $12.1-16.8$ & $<0.01$ \\
\hline $70-80$ & 92.6 & 53.1 & $42.5-66.4$ & $<0.01$ \\
\hline $80+$ & 344.5 & 194.1 & $94.5-398.6$ & $<0.01$ \\
\hline \multicolumn{5}{|l|}{ Sex } \\
\hline Men & 1.0 (ref) & 1.0 (ref) & & \\
\hline Women & 1.0 & 0.9 & $0.8-1.0$ & 0.14 \\
\hline \multicolumn{5}{|l|}{ Monthly household income } \\
\hline Lowest quintile & 1.0 (ref) & 1.0 (ref) & & \\
\hline 2nd to 4th quintile & 0.2 & 0.9 & $0.7-1.0$ & 0.05 \\
\hline Highest quintile & 0.1 & 0.7 & $0.6-0.9$ & $<0.01$ \\
\hline \multicolumn{5}{|l|}{ Education } \\
\hline Elementary school & 1.0 (ref) & 1.0 (ref) & & \\
\hline Middle school & 0.3 & 0.8 & $0.7-0.9$ & $<0.01$ \\
\hline High school & 0.2 & 0.7 & $0.6-0.8$ & $<0.01$ \\
\hline University or higher & 0.1 & 0.6 & $0.5-0.7$ & $<0.01$ \\
\hline \multicolumn{5}{|c|}{ 2. Health examination variable } \\
\hline \multicolumn{5}{|l|}{ Hypercholesterolemia } \\
\hline No & 1.0 (ref) & 1.0 (ref) & & \\
\hline Yes & 1.5 & 1.2 & $1.0-1.3$ & 0.02 \\
\hline \multicolumn{5}{|l|}{ Anemia } \\
\hline No & 1.0 (ref) & 1.0 (ref) & & \\
\hline Yes & 1.3 & 1.1 & $0.9-1.3$ & 0.18 \\
\hline \multicolumn{5}{|l|}{ Metabolic syndrome } \\
\hline No & 1.0 (ref) & 1.0 (ref) & & \\
\hline Yes & 2.1 & 1.1 & $0.9-1.2$ & 0.32 \\
\hline \multicolumn{5}{|l|}{ 3. Comorbidities } \\
\hline \multicolumn{5}{|l|}{ Hypertension } \\
\hline No & 1.0 (ref) & 1.0 (ref) & & \\
\hline Yes & 3.1 & 1.1 & $1.0-1.3$ & 0.02 \\
\hline \multicolumn{5}{|l|}{ Diabetic mellitus } \\
\hline No & 1.0 (ref) & 1.0 (ref) & & \\
\hline Yes & 3.1 & 1.6 & $1.3-1.9$ & $<0.01$ \\
\hline
\end{tabular}

Because cataract prevalence is not rare, we were confident we could perform additional analyses of relative risks (and their 95\% CIs) to avoid exaggerated interactions in Table 7. When we considered hypertension and DM, participants who had only DM were more likely to have cataracts than those with only hypertension, and those with both hypertension and DM were two times more likely to have cataracts than those with neither hypertension nor DM (Table 7).
Hypertension has been of interest as a risk factor in previous studies. Cross-sectional analysis on an initial Beaver Dam Eye cohort showed a correlation between hypertension and posterior subcapsular type [43], whereas a Blue Mountain Eye cohort (from 10-year incidence data) had a relationship with a high rate of cataract surgery [44]. A recent cross-sectional study from the Los Angeles Latino Eye Study showed a relationship between hypertension and 
Table 6 Factors associated with risks of developing subtypes of cataracts - Final model $(\mathrm{N}=11,591)$

\begin{tabular}{|c|c|c|c|c|c|c|c|c|}
\hline & \multicolumn{2}{|c|}{ Pure Cortical type $n=7008$} & \multicolumn{2}{|c|}{ Pure Nuclear type } & \multicolumn{2}{|c|}{ Pure PSCO type } & \multicolumn{2}{|c|}{ Mixed type } \\
\hline & Multivariate $\mathrm{OR}$ & $\overline{p \text { value }}$ & Multivariate OR & $\overline{p \text { value }}$ & Multivariate OR & $p$ value & Multivariate OR & $p$ value \\
\hline \multicolumn{9}{|c|}{ 1. Socio-demographic factors } \\
\hline \multicolumn{9}{|l|}{ Age (years) } \\
\hline $40-49$ & 1.0 (ref) & & 1.0 (ref) & & 1.0 (ref) & & 1.0 (ref) & \\
\hline $50-59$ & 2.8 & $<0.01$ & 4.1 & $<0.01$ & 3.2 & 0.07 & 4.1 & $<0.01$ \\
\hline $60-69$ & 9.0 & $<0.01$ & 15.7 & $<0.01$ & 6.9 & $<0.01$ & 22.6 & $<0.01$ \\
\hline $70-80$ & 26.4 & $<0.01$ & 44.8 & $<0.01$ & 24.1 & $<0.01$ & 104.3 & $<0.01$ \\
\hline $80+$ & 59.6 & $<0.01$ & 138.2 & $<0.01$ & 135.9 & $<0.01$ & 414.0 & $<0.01$ \\
\hline \multicolumn{9}{|l|}{ Sex } \\
\hline Men & 1.0 (ref) & & 1.0 (ref) & & 1.0 (ref) & & 1.0 (ref) & \\
\hline Women & 0.9 & 0.07 & 1.0 & 0.87 & 1.0 & 0.92 & 1.1 & 0.50 \\
\hline \multicolumn{9}{|c|}{ Monthly household income } \\
\hline Lowest quintile & 1.0 (ref) & & 1.0 (ref) & & 1.0 (ref) & & 1.0 (ref) & \\
\hline 2nd to 4 th quintile & 0.7 & $<0.01$ & 1.0 & 0.97 & 0.5 & 0.07 & 0.8 & 0.02 \\
\hline Highest quintile & 0.7 & $<0.01$ & 1.0 & 0.78 & 0.4 & 0.12 & 0.6 & $<0.01$ \\
\hline \multicolumn{9}{|l|}{ Education } \\
\hline Elementary school & 1.0 (ref) & & 1.0 (ref) & & 1.0 (ref) & & 1.0 (ref) & \\
\hline Middle school & 0.8 & 0.11 & 0.8 & 0.02 & 0.7 & 0.52 & 0.8 & 0.11 \\
\hline High school & 0.6 & $<0.01$ & 0.8 & 0.02 & 1.0 & 0.93 & 0.6 & $<0.01$ \\
\hline Univ. or higher & 0.5 & $<0.01$ & 0.6 & $<0.01$ & 0.9 & 0.93 & 0.9 & 0.56 \\
\hline \multicolumn{9}{|c|}{ 2. Health examination variable } \\
\hline \multicolumn{9}{|l|}{ Hypercholesterolemia } \\
\hline No & 1.0 (ref) & & 1.0 (ref) & & 1.0 (ref) & & 1.0 (ref) & \\
\hline Yes & 1.3 & 0.02 & 1.0 & 0.61 & 1.6 & 0.28 & 1.1 & 0.26 \\
\hline \multicolumn{9}{|l|}{ Anemia } \\
\hline No & 1.0 (ref) & & 1.0 (ref) & & 1.0 (ref) & & 1.0 (ref) & \\
\hline Yes & 0.9 & 0.70 & 1.1 & 0.29 & 1.0 & 0.96 & 1.3 & 0.12 \\
\hline \multicolumn{9}{|l|}{ Metabolic syndrome } \\
\hline No & 1.0 (ref) & & 1.0 (ref) & & 1.0 (ref) & & 1.0 (ref) & \\
\hline Yes & 0.9 & 0.23 & 1.2 & 0.02 & 0.6 & 0.17 & 1.2 & 0.13 \\
\hline \multicolumn{9}{|l|}{ 3. Comorbidities } \\
\hline \multicolumn{9}{|l|}{ Hypertension } \\
\hline No & 1.0 (ref) & & 1.0 (ref) & & 1.0 (ref) & & 1.0 (ref) & \\
\hline Yes & 1.2 & 0.14 & 1.0 & 0.88 & 1.1 & 0.86 & 1.2 & 0.16 \\
\hline \multicolumn{9}{|l|}{ Diabetic mellitus } \\
\hline No & 1.0 (ref) & & 1.0 (ref) & & 1.0 (ref) & & 1.0 (ref) & \\
\hline Yes & 1.3 & 0.05 & 1.4 & $<0.01$ & 2.7 & 0.04 & 1.4 & 0.02 \\
\hline
\end{tabular}

both posterior subcapsular and mixed type cataracts [45]. In our study, we were only able to show a relationship between hypertension and the "overall" cataract population.

\section{Hypercholesterolemia}

Although some studies have shown that statins have a protective effect against cataract development, not only because of their cholesterol-lowering effects but also possibly due to anti-oxidative and/or anti-inflammatory effects $[46,47]$, dyslipidemia might still be a risk factor for cataract development. In our study, we included hyper-Low-Density-Lipoproteinemia (hyper-LDL), hypoHigh Density Lipoproteinemia (hypo-HDL), and hypertriglycemia (hyper-TG) as separate variables in our initial 
Table 7 Modification of the effect of diabetes mellitus on risk of developing cataracts by hypertension

\begin{tabular}{|c|c|c|c|c|c|}
\hline \multirow[b]{3}{*}{ Hypertension } & \multicolumn{4}{|c|}{ Diabetes Mellitus (DM) } & \multirow{3}{*}{$\begin{array}{l}\text { RR }(95 \% \mathrm{Cl}) ; p \text { for } \\
\text { with versus without } \\
\text { DM within strata } \\
\text { of hypertension }\end{array}$} \\
\hline & \multicolumn{2}{|c|}{ No } & \multicolumn{2}{|c|}{ Yes } & \\
\hline & $\%$ & RR (95\% CI) & $\%$ & RR $(95 \% \mathrm{Cl})$ & \\
\hline No & $2852 / 7502(38 \%)$ & 1.0 & $345 / 531(65 \%)$ & $1.7(1.4-2.2) p<0.01$ & $1.7(1.4-2.2) p<0.01$ \\
\hline Yes & $1757 / 2735(64 \%)$ & $1.2(1.1-1.3) p<0.01$ & $565 / 736(77 \%)$ & $2.0(1.6-2.5) p<0.01$ & $1.1(0.9-1.5) p=0.37$ \\
\hline
\end{tabular}

Measure of effect modification on additive scale: RERI $(95 \% \mathrm{Cl})=0.1(-0.5 \sim 0.6) ; \mathrm{p}=0.85$.

Measure of effect modification on multiplicative scale: ratio of RRs $(95 \% \mathrm{Cl})=1.0(0.7 \sim 1.3) ; \mathrm{p}=0.78$.

RRs are adjusted for age, sex, household monthly income, and education.

$\mathrm{RR}$ : relative risk, $\mathrm{RERI}$; relative excess risk due to interaction, $\mathrm{Cl}$; confidence interval.

univariate logistic analysis (Table 3), and we later showed that hypercholesterolemia was the only independent risk factor for cataracts after multivariate logistic analysis $(\mathrm{aOR}=1.2 ; 95 \% \mathrm{CI}, 1.0-1.3)$. Further tests on the association between nutrition and cataract development might reveal more information.

\section{Metabolic syndrome}

Abdominal obesity is associated with insulin resistance on peripheral glucose and fatty acid utilization, often leading to co-occurrence of metabolic risk factors for type $2 \mathrm{DM}$, dyslipidemia, hypertension, and cardiovascular diseases $[48,49]$. These studies evaluated metabolic syndrome as an independent risk factor for cataracts, but when more components of the metabolic syndrome were included in a prospective cohort study, more risk was reported [50]. In our study, metabolic syndrome was an independent risk factor for the pure nuclear cataract type (Table 4).

There are some limitations to this study since the KNHANES and its ophthalmologic examinations aimed to investigate various health issues, limited resources were allocated for investigating cataract and subtypes. First, iridodilators could not be used, which could have influenced the detection and classification of the cataract, even though the examiners maximized the pupil diameter with the illuminator and slit lamp settings described in the Methods section, this could have been an underestimation of cataract prevalence. Misclassification and under estimation were possible, especially for the cortical type of cataract when it occurs in the peripheral cortex in a circumferential or in an arcuate pattern. Second, the cut value of opalescence based on LOCS III score was not included, which could induce individual variation between ophthalmologists; however, while grading and classifying by a few ophthalmologists may increase the accuracy of the result, a systemic error could also increase. This could reflect the generally accepted definition of cataract from a number of ophthalmologists. Third, the ophthalmologic exam for this study was done with a slit lamp without a permanent photographic record, which could have restricted the reviewing or assessment of inter-observer reliability for the classification. Despite these limitations, we believe our study adequately identified risk factors most associated with cataract development, particularly at the national level.

\section{Conclusions}

We were able to show that socioeconomic disparities do exist in cataract development, and improved control of blood pressure, sugar, cholesterol and the factors associated with metabolic syndrome may help to reduce the risk of cataract development. For individuals who have both hypertension and DM, the risk of developing cataracts was twice than that of the individuals without. Therefore, we recommend more targeted efforts to reduce such risks in this group.

\section{Competing interests}

The authors have no proprietary or commercial interest in any materials discussed in this article.

\section{Authors' contributions}

THTR and MK drafted the manuscript. THTR and WCK carried out the statistical analysis. WCK interpreted the data. TK and EKK prepare and review of the manuscript. EKK participated in study design. This survey was conducted by Epidemiologic Survey Committee of the Korean Ophthalmologic Society. All authors read and approved the final manuscript.

\section{Acknowledgments}

This research was supported by the Converging Research Center Program funded by the Ministry of Education, Science and Technology (2012 K001354).

This survey was conducted under supervision of Epidemiologic Survey Committee of the Korean Ophthalmological Society.

\section{Author details}

${ }^{1}$ Department of Ophthalmology, Yonsei University College of Medicine, 50 Yonsei-ro, Seodaemun-gu, Seoul, Korea. ${ }^{2}$ Seoul National University College of Medicine, Seoul, Republic of Korea. ${ }^{3}$ Hwaseong City Health Center, Hwaseong-si, Gyeonggi-do, Korea. ${ }^{4}$ Emory University School of Medicine, 30322 Atlanta, Georgia, USA. ${ }^{5}$ Corneal Dystrophy Research Institute, Yonsei University College of Medicine, Seoul, Korea. 'Severance Biomedical Science Institute, Yonsei University College of Medicine, Seoul, Korea. ${ }^{7}$ Brain Korea 21 Project for Medical Science, Yonsei University, Seoul, Korea.

Received: 11 June 2013 Accepted: 2 January 2014

Published: 10 January 2014 


\section{References}

1. Hiller R, Sperduto RD, Ederer F: Epidemiologic associations with nuclear, cortical, and posterior subcapsular cataracts. Am J Epidemiol 1986, 124(6):916-925.

2. Klein R, Klein BE, Jensen SC, Moss SE, Cruickshanks KJ: The relation of socioeconomic factors to age-related cataract, maculopathy, and impaired vision. The Beaver Dam Eye Study. Ophthalmology 1994, 101 (12):1969-1979.

3. Hiller R, Sperduto RD, Podgor MJ, Wilson PW, Ferris FL 3rd, Colton T, D'Agostino RB, Roseman MJ, Stockman ME, Milton RC: Cigarette smoking and the risk of development of lens opacities. The Framingham studies. Arch Ophthalmol 1997, 115(9):1113-1118.

4. Hennis A, Wu SY, Nemesure B, Leske MC: Risk factors for incident cortical and posterior subcapsular lens opacities in the Barbados Eye Studies. Arch Ophthalmol 2004, 122(4):525-530.

5. Klein BE, Klein R, Lee KE: Diabetes, cardiovascular disease, selected cardiovascular disease risk factors, and the 5-year incidence of age-related cataract and progression of lens opacities: the Beaver Dam Eye Study. Am J Ophthalmol 1998, 126(6):782-790.

6. Bochow TW, West SK, Azar A, Munoz B, Sommer A, Taylor HR: Ultraviolet light exposure and risk of posterior subcapsular cataracts. Arch Ophthalmol 1989, 107(3):369-372.

7. Cruickshanks KJ, Klein BE, Klein R: Ultraviolet light exposure and lens opacities: the Beaver Dam Eye Study. Am J Public Health 1992, 82(12):1658-1662.

8. Caulfield LE, West SK, Barron Y, Cid-Ruzafa J: Anthropometric status and cataract: the Salisbury Eye Evaluation project. Am J Clin Nutr 1999, 69(2):237-242.

9. Glynn RJ, Christen WG, Manson JE, Bernheimer J, Hennekens CH: Body mass index. An independent predictor of cataract. Arch Ophthalmol 1995, 113(9):1131-1137.

10. Hiller R, Podgor MJ, Sperduto RD, Nowroozi L, Wilson PW, D'Agostino RB, Colton T: A longitudinal study of body mass index and lens opacities. The Framingham Studies. Ophthalmology 1998, 105(7):1244-1250.

11. Cumming RG, Mitchell P, Leeder SR: Use of inhaled corticosteroids and the risk of cataracts. N Engl J Med 1997, 337(1):8-14.

12. Klein $B E$, Klein $R$, Lee KE, Danforth LG: Drug use and five-year incidence of age-related cataracts: The Beaver Dam Eye Study. Ophthalmology 2001, 108(9):1670-1674.

13. Del Castillo JM B, Del Rio T, Garcia-Sanchez J: Effects of estrogen use on lens transmittance in postmenopausal women. Ophthalmology 1997, 104(6):970-973.

14. Kanthan GL, Wang JJ, Burlutsky G, Rochtchina E, Cumming RG, Mitchell P: Exogenous oestrogen exposure, female reproductive factors and the long-term incidence of cataract: the Blue Mountains Eye Study. Acta ophthalmologica 2010, 88(7):773-778.

15. Klein $B E$, Klein R, Ritter $L L:$ Is there evidence of an estrogen effect on age-related lens opacities? The Beaver Dam Eye Study. Arch Ophthalmol 1994, 112(1):85-91.

16. DE RSDEEP, DE CATARATA P: Systematic review of population-based studies of the prevalence of cataracts. Arch Soc Esp Oftalmol 2006, 81:509-516.

17. Kanthan GL, Wang JJ, Rochtchina E, Tan AG, Lee A, Chia EM, Mitchell P: Ten-year incidence of age-related cataract and cataract surgery in an older Australian population. The Blue Mountains Eye Study. Ophthalmology 2008, 115(5):808-814 e801.

18. Congdon N, Vingerling J, Klein B, West S, Friedman D, Kempen J, O'Colmain B, Wu S, Taylor H: Prevalence of cataract and pseudophakia/aphakia among adults in the United States. Arch Ophthalmol 2004, 122(4):487.

19. Sasaki K, Sasaki H, Jonasson F, Kojima M, Cheng HM: Racial differences of lens transparency properties with aging and prevalence of age-related cataract applying a WHO classification system. Ophthalmic research 2004 36(6):332-340.

20. Seah SKL, Wong TY, Foster PJ, Ng TP, Johnson GJ: Prevalence of lens opacity in Chinese residents of Singapore: the tanjong pagar survey. Ophthalmology 2002, 109(11):2058-2064.

21. Xu L, Cui T, Zhang S, Sun B, Zheng Y, Hu A, Li J, Ma K, Jonas JB: Prevalence and risk factors of lens opacities in urban and rural Chinese in Beijing. Ophthalmology 2006, 113(5):747-755.

22. Foster P, Wong T, Machin D, Johnson G, Seah S: Risk factors for nuclear, cortical and posterior subcapsular cataracts in the Chinese population of Singapore: the Tanjong Pagar Survey. Br J Ophthalmol 2003, 87(9):1112-1120.
23. Yoon KC, Mun GH, Kim SD, Kim SH, Kim CY, Park KH, Park YJ, Baek SH, Song SJ, Shin JP, et al: Prevalence of eye diseases in South Korea: data from the Korea National Health and Nutrition Examination Survey 2008-2009. Korean J Ophthalmol 2011, 25(6):421-433.

24. Lim HT, Yoon JS, Hwang SS, Lee SY: Prevalence and associated sociodemographic factors of myopia in Korean children: the 2005 third Korea National Health and Nutrition Examination Survey (KNHANES III). Japanese journal of ophthalmology 2012, 56(1):76-81.

25. Deaton A, Lubotsky D: Mortality, inequality and race in American cities and states. Social science \& medicine 2003, 56(6):1139-1153.

26. World Health Organization, Department of Mental Health Substance Dependence, Noncommunicable Diseases Mental Health Cluster: International guide for monitoring alcohol consumption and related harm. Geneva: World Health Organization; 2000.

27. Cigarette smoking among adults-United States 1992 and changes in the definition of current cigarette smoking. MMWR Morb Mortal Wkly Rep 1994, 43:343-346.

28. Alberti KG, Eckel RH, Grundy SM, Zimmet PZ, Cleeman Jl, Donato KA, Fruchart JC, James WP, Loria CM, Smith SC Jr: Harmonizing the metabolic syndrome: a joint interim statement of the International Diabetes Federation Task Force on Epidemiology and Prevention; National Heart, Lung, and Blood Institute; American Heart Association; World Heart Federation; International Atherosclerosis Society; and International Association for the Study of Obesity. Circulation 2009, 120(16):1640-1645.

29. Lee SY, Park HS, Kim DJ, Han JH, Kim SM, Cho GJ, Kim DY, Kwon HS, Kim SR, Lee $C B$, et al: Appropriate waist circumference cutoff points for central obesity in Korean adults. Diabetes research and clinical practice 2007, 75(1):72-80.

30. Athanasiov PA, Casson RJ, Sullivan T, Newland HS, Shein WK, Muecke JS, Selva D, Aung T: Cataract in rural Myanmar: prevalence and risk factors from the Meiktila Eye Study. The British journal of ophthalmology 2008, 92(9):1169-1174.

31. Vashist P, Talwar B, Gogoi M, Maraini G, Camparini M, Ravindran RD, Murthy GV, Fitzpatrick KE, John N, Chakravarthy U, et al: Prevalence of cataract in an older population in India: the India study of age-related eye disease. Ophthalmology 2011, 118(2):272-278-e271-272.

32. Tsai S-Y, Hsu W-M, Cheng C-Y, Liu J-H, Chou P: Epidemiologic study of age-related cataracts among an elderly chinese population in Shih-Pai, Taiwan. Ophthalmology 2003, 110(6):1089-1095.

33. Shah SP, Dineen B, Jadoon Z, Bourne R, Khan MA, Johnson GJ, Stavola BD, Gilbert C, Khan MD: Lens opacities in adults in Pakistan: prevalence and risk factors. Ophthalmic epidemiology 2007, 14(6):381-389.

34. Hammond CJ, Snieder H, Spector TD, Gilbert CE: Genetic and environmental factors in age-related nuclear cataracts in monozygotic and dizygotic twins. N Engl J Med 2000, 342(24):1786-1790.

35. Klein BE, Klein R, Lee KE, Gangnon RE: Incidence of age-related cataract over a 15-year interval the Beaver Dam Eye Study. Ophthalmology 2008, 115(3):477-482.

36. Robman $\mathrm{L}$, Taylor $\mathrm{H}$ : External factors in the development of cataract. Eye 2005, 19(10):1074-1082.

37. Klein BEK, Klein R, Lee KE, Meuer SM: Socioeconomic and lifestyle factors and the 10-year incidence of age-related cataracts. Am J Ophthalmol 2003, 136(3):506-512.

38. Leske MC, Wu SY, Hennis A, Connell AM, Hyman L, Schachat A: Diabetes, hypertension, and central obesity as cataract risk factors in a black population. The Barbados Eye Study. Ophthalmology 1999, 106(1):35-41.

39. Leske MC, Chylack LT Jr, Wu SY: The Lens Opacities Case-control Study. Risk factors for cataract. Arch Ophthalmol 1991, 109(2):244-251.

40. Szmyd L Jr, Schwartz B: Association of systemic hypertension and diabetes mellitus with cataract extraction. A case-control study. Ophthalmology 1989, 96(8):1248-1252.

41. Kanthan GL, Mitchell P, Burlutsky G, Wang JJ: Fasting blood glucose levels and the long-term incidence and progression of cataract - the Blue Mountains Eye Study. Acta ophthalmologica 2011, 89(5):e434-e438.

42. Leske MC, Wu SY, Nemesure B, Hennis A: Risk factors for incident nuclear opacities. Ophthalmology 2002, 109(7):1303-1308.

43. Klein B, Klein R, Jensen SC, Linton K: Hypertension and lens opacities from the Beaver Dam Eye Study. Am J Ophthalmol 1995, 119(5):640.

44. Tan JS, Wang JJ, Mitchell P: Influence of diabetes and cardiovascular disease on the long-term incidence of cataract: the Blue Mountains eye study. Ophthalmic Epidemiol 2008, 15(5):317-327. 
45. Richter GM, Torres M, Choudhury F, Azen SP, Varma R: Risk Factors for Cortical, Nuclear, Posterior Subcapsular, and Mixed Lens Opacities: The Los Angeles Latino Eye Study. Ophthalmology 2012, 119(3):547-554.

46. Klein BEK, Klein R, Lee KE, Grady LM: Statin use and incident nuclear cataract. JAMA: the journal of the American Medical Association 2006, 295(23):2752.

47. Tan JSL, Mitchell P, Rochtchina E, Wang JJ: Statin use and the long-term risk of incident cataract: the Blue Mountains Eye Study. Am J Ophthalmol 2007, 143(4):687-689.

48. Isomaa B, Almgren P, Tuomi T, Forsén B, Lahti K, Nissén M, Taskinen MR, Groop L: Cardiovascular morbidity and mortality associated with the metabolic syndrome. Diabetes care 2001, 24(4):683.

49. Alberti KG, Zimmet $P$, Shaw J: The metabolic syndrome-a new worldwide definition. Lancet 2005, 366(9491):1059.

50. Lindblad BE, Hakansson N, Philipson B, Wolk A: Metabolic syndrome components in relation to risk of cataract extraction: a prospective cohort study of women. Ophthalmology 2008, 115(10):1687-1692.

doi:10.1186/1471-2415-14-4

Cite this article as: Rim et al:: Cataract subtype risk factors identified from the Korea National Health and Nutrition Examination survey 2008-2010. BMC Ophthalmology 2014 14:4.

\section{Submit your next manuscript to BioMed Central and take full advantage of:}

- Convenient online submission

- Thorough peer review

- No space constraints or color figure charges

- Immediate publication on acceptance

- Inclusion in PubMed, CAS, Scopus and Google Scholar

- Research which is freely available for redistribution 